\title{
Conversion of endoscopic ultrasound-guided hepaticogastrostomy to transpapillary drainage by anterograde intervention via dedicated biliary metal stent for benign biliary stenosis
}

An 80-year-old woman with obstructive jaundice caused by distal biliary stenosis secondary to chronic pancreatitis was referred for biliary drainage. After failed endoscopic retrograde cholangiopancreatography, endoscopic ultrasound (EUS)guided biliary drainage was proposed. Portal cavernomatosis prevented an extrahepatic route and EUS-hepaticogastrostomy (HGS) was considered.

Using a linear echoendoscope, the left biliary duct was accessed with a 19-gauge needle. The tract diameter was increased using a 6-Fr cystotome and 4-mm balloon catheter. A partially covered biliary self-expandable metal stent (SEMS; $8 \times 80$ mm Niti-S Giobor stent; Taewoong Medical, Goyang-si, South Korea) was placed (> Fig. 1).

Endoscopic anterograde transhepatic intervention was attempted 6 weeks later through the mature EUS-HGS fistula. Anterograde cholangioscopy using a pediatric scope through the transhepatic SEMS showed tissue ingrowth at the uncovered end $(2.4 \mathrm{~cm})$, occluding the distal stent lumen. The Giobor stent was

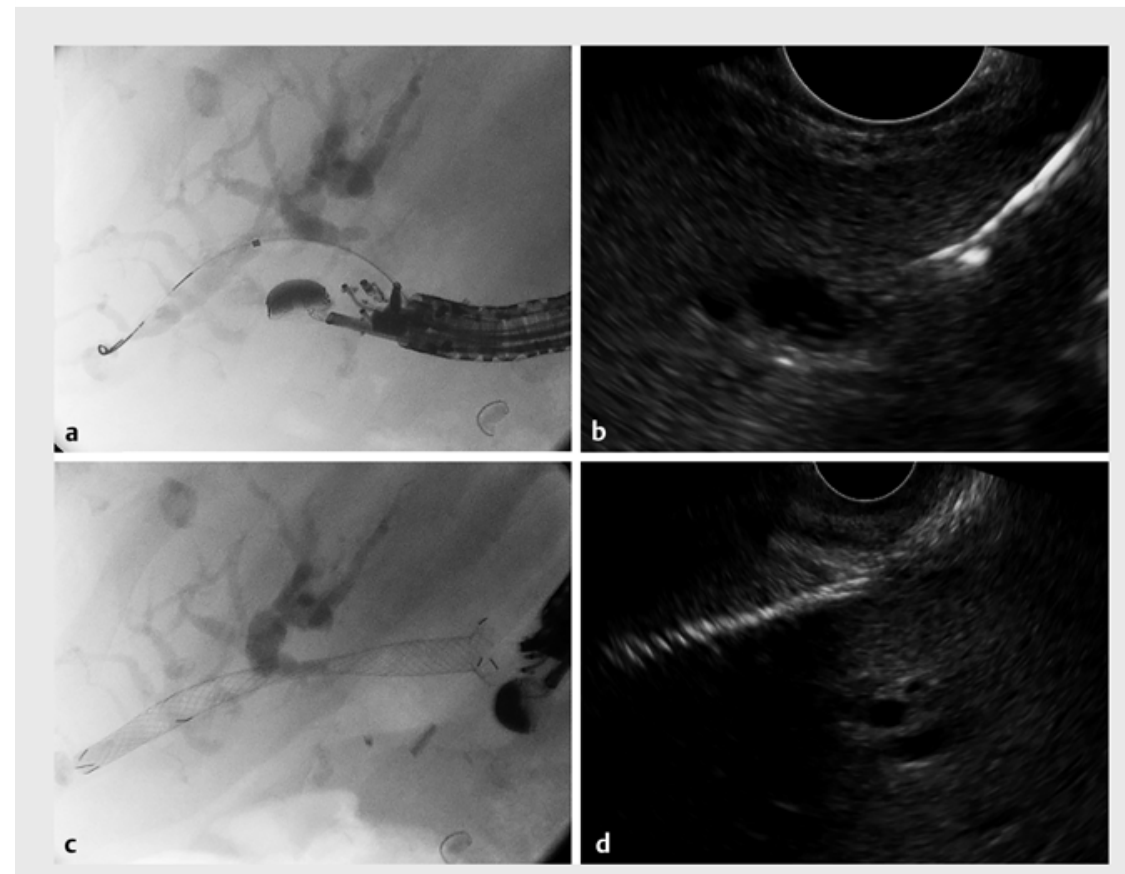

- Fig. 1 Endoscopic ultrasound (EUS)-guided hepaticogastrostomy. a Dilation of the transmural fistula under fluoroscopic guidance. b Endosonography image of intrahepatic duct and guidewire. c, $\mathbf{d}$ Placement of dedicated biliary metal stent $(8 \times 80 \mathrm{~mm} ; 70 \%$ covered, $30 \%$ bare; Niti-S Giobor Biliary stent; Taewoong Medical, Goyang-si, South Korea) by fluoroscopic (c) and EUS (d) guidance.
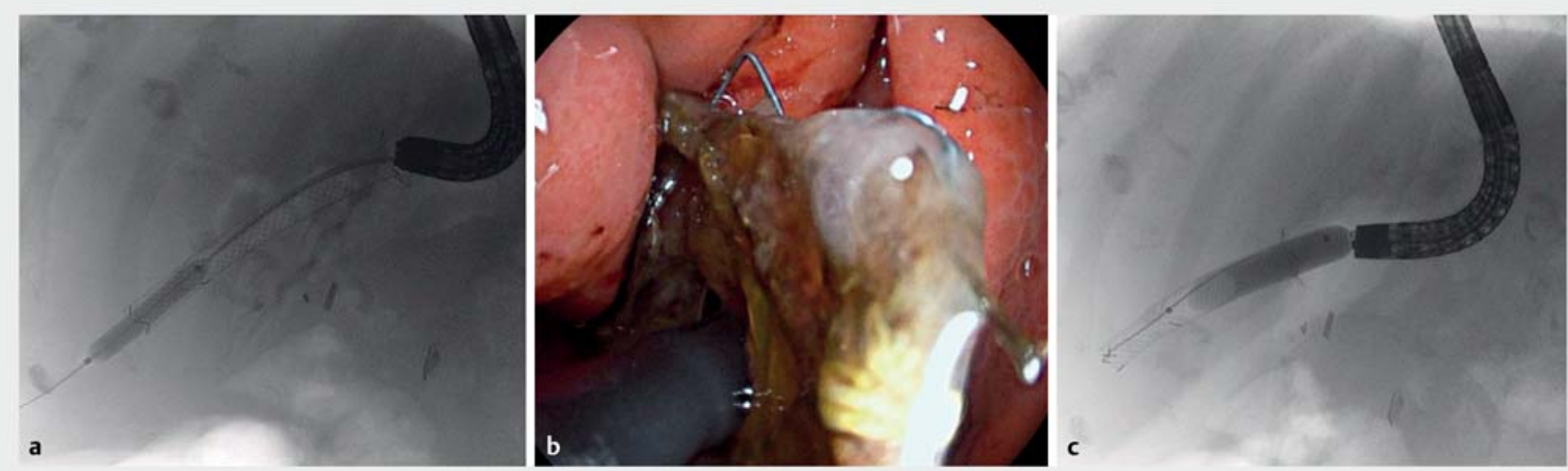

- Fig. 2 Maximal intrastent dilation up to 8 and $10 \mathrm{~mm}$ of the distal bare portion (Giobor stent) by fluoroscopic guidance. a, c Fluoroscopic images; b endoscopic image. 

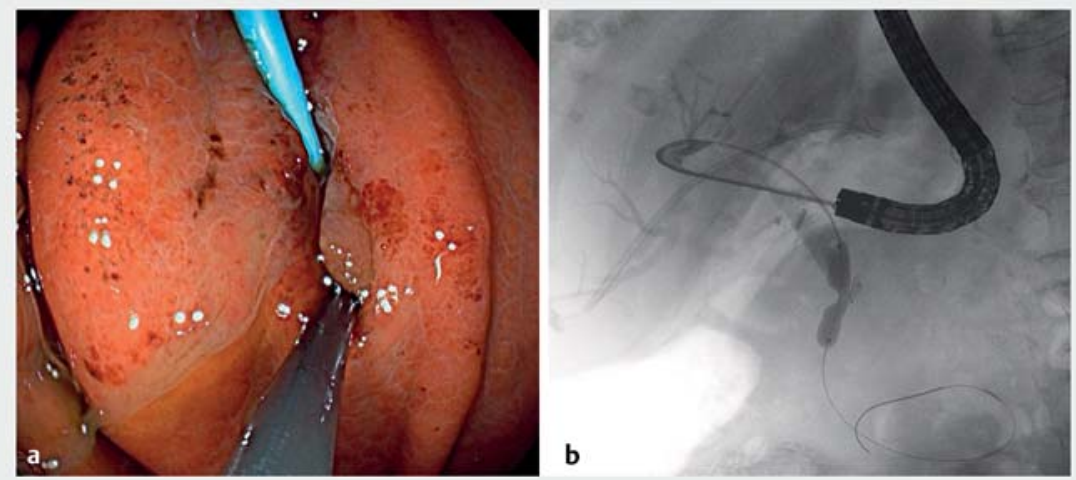

- Fig. 3 Endoscopic transhepatic anterograde intervention. a Balloon catheter and plastic stent within the mature hepaticogastrostomy fistula. b Anterograde dilation of extrahepatic distal biliary stenosis up to $8 \mathrm{~mm}$, guided by fluoroscopy.
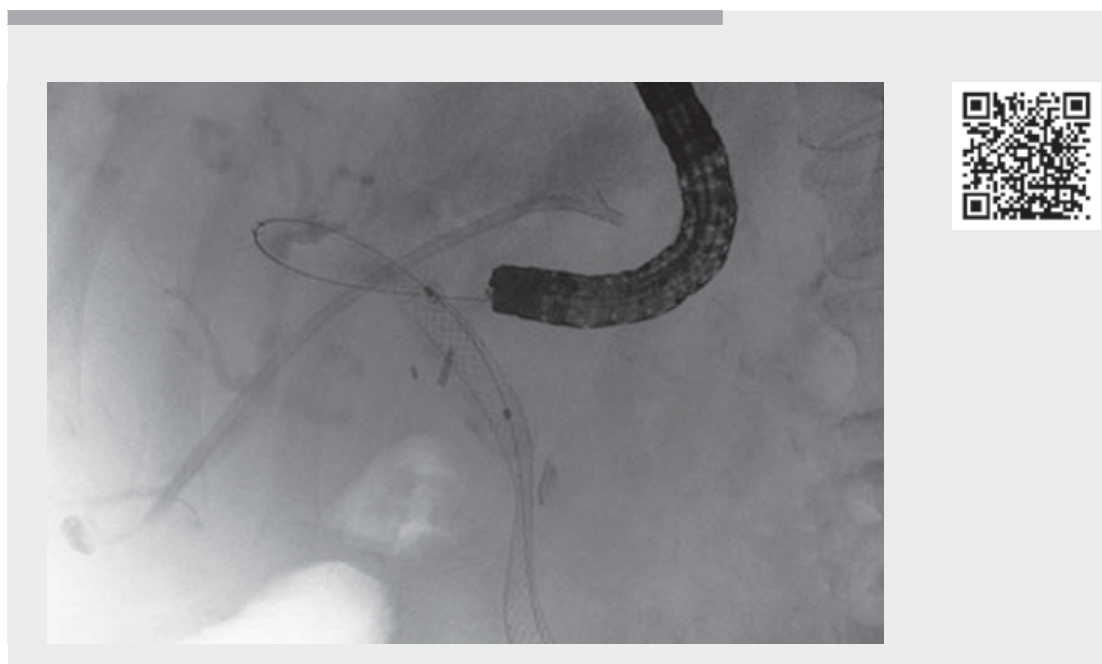

Video 1 Conversion of endoscopic ultrasound-guided hepaticogastrostomy to transpapillary drainage by anterograde intervention using a dedicated biliary metal stent in a benign distal biliary stenosis.

removed using a grasping forceps after maximal intrastent balloon dilation ( Fig. 2). The fistula tract was explored by anterograde cholangioscopy, identifying intrahepatic ducts close to the gastric wall. Scope exchange to a therapeutic scope allowed cholangiography using an impacted balloon extractor, and a biliary roadmap was captured. Next, a plastic stent $(8.5 \mathrm{Fr} \times 9 \mathrm{~cm})$ was placed across the HGS fistula to secure guidewire passage in the desired anterograde transpa-
The Giobor stent is a dedicated biliary stent for HGS and has been reported for use in malignant diseases but not as a temporary stent [1-5]. The recent change in covered design ( $70 \%: 30 \%)$ enables its use in a biliary benign scenario as a temporary stent to create a transhepatic mature fistula, allowing subsequent anterograde stenting.

Endoscopy_UCTN_Code_TTT_1AS_2AG

\section{Competing interests}

JBG is a consultant for Boston Scientific.

The authors

Antonio Martinez-Ortega ${ }^{1,2}$, Albert GarciaSumalla' ${ }^{\circledR}$, Sergio Bazaga ${ }^{1}$, Julio G. VelasquezRodriguez ${ }^{1}$, Sandra Maisterra ${ }^{1}$, Joan B.

Gornals ${ }^{1,3} 3$

1 Endoscopy Unit, Department of Digestive Diseases, Hospital Universitari de Bellvitge, Bellvitge Biomedical Research Institute (IDIBELL), University of Barcelona, Catalonia, Spain

2 Endoscopy Unit, Department of Digestive Diseases, Hospital Universitario Ramon y Cajal, Madrid

3 Faculty of Health Sciences, Universitat Oberta de Catalunya, Barcelona, Catalonia, Spain

Corresponding author

\section{Joan B. Gornals, MD, PhD}

Endoscopy Unit, Department of Digestive Diseases, Hospital Universitari de Bellvitge IDIBELL (Bellvitge Biomedical Research Institute), Feixa Llarga s/n, 08907 L'Hospitalet de Llobregat, Barcelona, Catalonia, Spain jgornals@bellvitgehospital.cat 
[1] De Cassan C, Bories E, Pesenti C et al. Use of partially covered and uncovered metallic prosthesis for endoscopic ultrasound-guided hepaticogastrostomy: results of a retrospective monocentric study. Endosc Ultrasound 2017; 6: 329-335

[2] Nakai Y, Sato T, Hakuta R et al. Long-term outcomes of a long, partially covered metal stent for EUS-guided hepaticogastrostomy in patients with malignant biliary obstruction (with video). Gastrointest Endosc 2020; 92: 623-631

[3] Ogura T, Takenaka M, Shiomi H et al. Longterm outcomes of EUS-guided transluminal stent deployment for benign biliary disease: multicenter clinical experience (with videos). Endosc Ultrasound 2019; 8: 398-403

[4] Dorrell R, Madigan K, Pawa S et al. Antegrade therapy for management of choledo- cholithiasis through endoscopic ultrasoundguided hepaticogastrostomy in a patient with surgically altered gastrointestinal anatomy. Case Rep Gastrointest Med 2020; 2020: 8866899

[5] Sato T, Nakai Y, Kogure $\mathrm{H}$ et al. Electrohydraulic lithotripsy through a fistula of EUSguided hepaticogastrostomy: a new approach for right intrahepatic stones. VideoGIE 2019; 4: 420-422

Bibliography

Endoscopy 2022; 54: E207-E209

DOI 10.1055/a-1486-6510

ISSN 0013-726X

published online 12.5.2021

(c) 2021. Thieme. All rights reserved.

Georg Thieme Verlag KG, Rüdigerstraße 14,

70469 Stuttgart, Germany
ENDOSCOPY E-VIDEOS

https://eref.thieme.de/e-videos

口居回 Endoscopy E-Videos is an

open access online section, 回: reporting on interesting cases and new techniques in gastroenterological endoscopy. All papers include a high quality video and all contributions are freely accessible online. Processing charges apply (currently EUR 375), discounts and wavers acc. to HINARI are available.

This section has its own submission website at

https://mc.manuscriptcentral.com/e-videos 